Int. J. Dev. Biol. 52: 473-480 (2008)

doi: $10.1387 / \mathrm{ijdb} .082583 \mathrm{bg}$

\title{
Sperm head membrane reorganisation during capacitation
}

\author{
BART M. GADELLA ${ }^{1, *}$, PEI-SHIUE TSAI ${ }^{1}$, ARJEN BOERKE${ }^{1}$ and IAN A. BREWIS²
}

\begin{abstract}
${ }^{1}$ Departments of Biochemistry \& Cell Biology and of Farm Animal Health, Faculty of Veterinary Medicine, Utrecht University, Utrecht, The Netherlands and ${ }^{2}$ Department of Medical Biochemistry and Immunology, School of Medicine, Cardiff University, United Kingdom
\end{abstract}

\begin{abstract}
The sperm cell has a characteristic polarized morphology and its surface is also highly differentiated into different membrane domains. Junctional protein ring structures seal the surface of the mid-piece from the head and the tail respectively and probably prevent random diffusion of membrane molecules over the protein rings. Despite the absence of such lateral diffusion-preventing structures, the sperm head surface is also highly heterogeneous. Furthermore, lipid and membrane protein ordering is subjected to changes when sperm become capacitated. The forces that maintain the lateral polarity of membrane molecules over the sperm surface, as well as those that cause their dynamic redistribution, are only poorly understood. Nevertheless, it is known that each of the sperm head surface regions has specific roles to allow sperm to fertilize the oocyte: a specific region is devoted to zona pellucida binding, a larger area of the sperm head surface is involved in the acrosome reaction (intracellular fusion), while yet another region is involved in egg plasma membrane binding and fertilization fusion (intercellular membrane fusion). All three events occur in the area of the sperm head where the plasma membrane covers the acrosome. Recently, lipid ordered microdomains (lipid rafts) were discovered in membranes of many biological specimens including sperm. In this review, we cover the latest insights about sperm lipid raft research and discuss how sperm lipid raft dynamics may relate to sperm-zona binding and the zona-induced acrosome reaction.
\end{abstract}

KEY WORDS: spermadhesin, fertilin, SNARE protein, lipid raft, cholesterol, epididymis, fertilization

\section{Introduction}

The mammalian sperm cell at the ejaculated stage has a highly differentiated morphology, which is reflected at its surface. Here the sperm head, mid-piece and tail are divided by the posterior ring and the annular ring structures, respectively (Eddy and O'Brien, 1994; Yanagamachi, 1994). These structures are supposed to function as a kind of junctional barrier for lipid exchange between the mid-piece and the head or tail. In particular, the sperm head surface shows lateral surface heterogeneity where at least four surface regions can be distinguished: the apical ridge area, the pre-equatorial surface area, the equatorial and the post equatorial surface areas (Fig. 1). In this context the sperm head does not contain junctional barriers to maintain these regions (De Leeuw et al., 1990) and thus to explain the lateral separation of many proteins and lipids that are observed (for review see Flesch and Gadella, 2000).

During sperm capacitation the membrane protein and lipid organization changes dramatically (Yanagimachi, 1994; Myles and Primakoff, 1984; Harrison et al., 1996; Suzuki-Toyota et al.,
2000; Cross et al., 2003; Harrison and Gadella 2005). It is these changes that most likely result in the capacitated state which characteristically allows the sperm to bind to the zona pellucida and immediately thereafter to acrosome react. It is obvious that certain sperm surface regions have specific roles in mammalian fertilization (see Fig. 2). For instance, the apical ridge is involved in sperm-zona binding and contains specific zona binding proteins that are absent, or at least not functional, at other parts of the sperm surface (O'Rand and Fischer, 1987). After zona binding, the sperm undergoes a rapid induction of the multiple fusions between the plasma membrane and the underlying outer acrosomal membrane, which is confined to the pre-equatorial surface area. This part of the sperm surface will form mixed vesicles with the outer acrosomal membrane during the acrosome reaction and will be shed by the sperm head (for references see Yanagimachi, 1994). Meanwhile, the inner acrosomal membrane takes over the function as the plasma membrane.

Abbreviations used in this paper: NSF, N-ethylmaleimide sensitive factor; SNARE, soluble NSF attachment receptor.

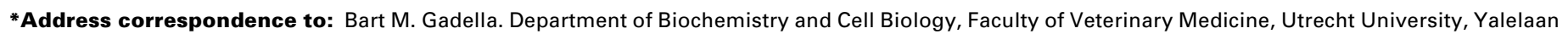
2, 3584 CM Utrecht, The Netherlands. Fax: +31-30-2535492. e-mail: B.M.Gadella@uu.nl
} 
A

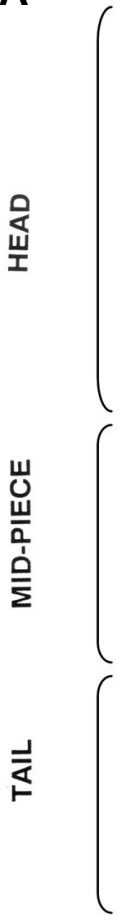

옾
B

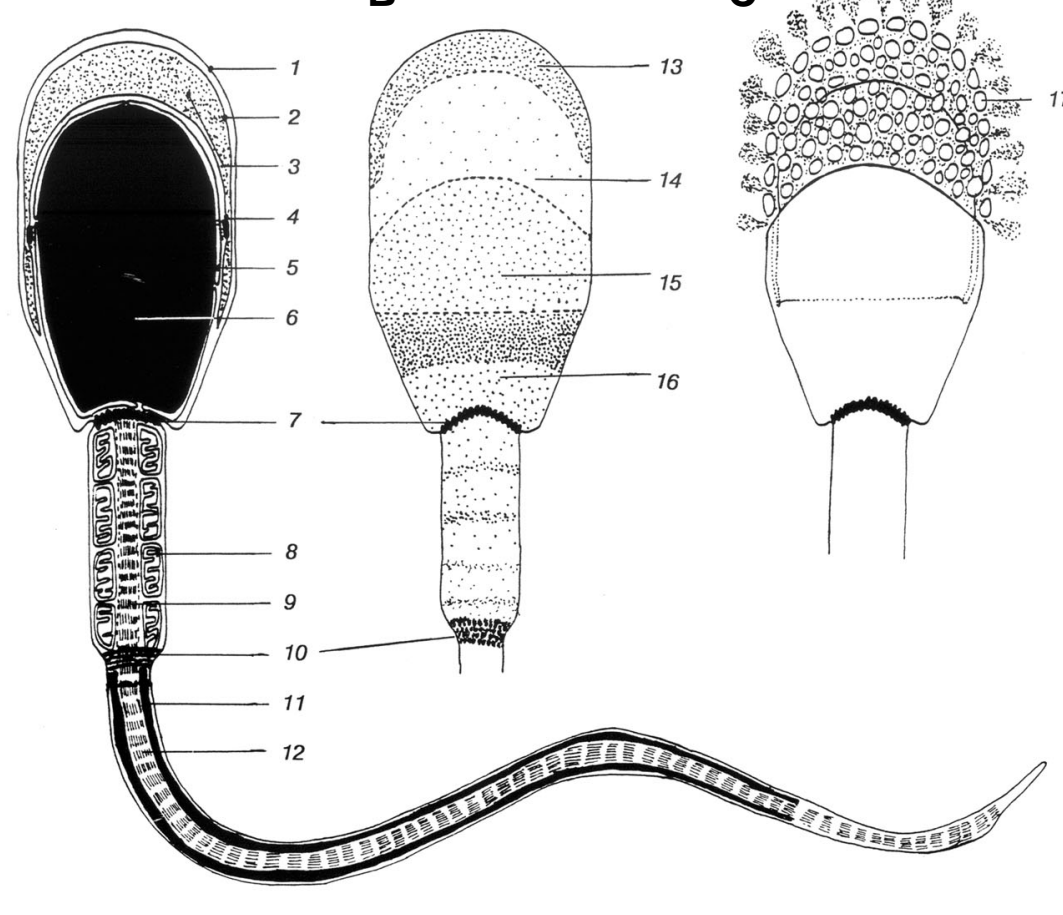

Fig. 1. Schematic representation of the boar sperm cell. (A) A sectional view of the sperm cell. All solid lines represent membrane bilayers 1, plasma membrane; 2 , outer acrosomal membrane; 3, acrosomal enzyme matrix; 4, inner acrosomal membrane; 5, nuclear envelope; 6 , nucleus; 7 , posterior ring and neck; 8, mitochondria; 9, proximal part of the flagellum; 10, annular ring; 11, fibrous sheath; 12, axoneme + outer dense fibers. (B) A surface view of the sperm head and midpiece with the subdomains 13, apical ridge; 14, pre-equatorial; 15, equatorial; 16, post-equatorial. (C) The acrosome reaction 17, the mixed vesicles formed during the acrosome reaction via multiple fusions between the plasma membrane and the outer acrosomal membrane. Note that the equatorial subdomain is not involved in such fusions. Modified from Gadella, 1994.

cellular membranes are constructed. In this model the membrane is organized as a bilayer of amphipathic phospholipids with the hydrophobic moieties (acyl chains) arranged next to each other and the hydrophilic part (the phosphate head groups) either at the cytoplasmic plasma monolayer interface, or at the extracellular monolayer (luminal monolayer for intracellular membranes). Cholesterol also behaves as an amphipathic molecule in both monolayers and the free hydroxyl group in cholesterol is the hydrophilic part, whereas the entire steroid backbone is the hydrophobic part. Due to the flat and non-flexible steroid backbone cholesterol stabilizes the membrane bilayer (Chapham, 1975).

In the mid 1970s it was realised that different membrane lipids were not randomly distributed over the transverse membrane bilayer (Verkleij et al., 1973; Hakomori and Igarashi, 1995). The amino-phospholipids phosphatidylserine (PS) and phosphatidylethanolamine (PE) were predominantly in the inner (cytosolic) lipid leaflet of the membrane bilayer, while glycolipids and the choline-phospholipids phosphatidylcholine (PC) and sphingomyelin (SM) were more confined to the outer/luminal leaflet of the membrane bilayer. Active phospholipid transporter proteins serve to establish or to disrupt the transverse phospholipid asymmetry (for review see Devaux etal., 2006).

The equatorial surface area of the sperm head is not involved in the acrosome reaction and a hairpin like structure traverses the posterior sperm head plasma membrane via the equatorial part of the outer acrosomal membrane to the inner acrosomal membrane. Noteworthy is the observation that this hairpin structure is the site of the sperm surface that is able to bind to the egg plasma membrane followed by the fertilization fusion and oocyte activation (for review see Yanagimachi, 1994). These processes are organized via delicate surface reordering processes and although we appreciate the functional importance of these events (we know why the surface is organized like it is), we do not really understand how the domains of the sperm surface are organized and subject to delicate rearrangements.

This review is intended to provide the latest insights into how lipid ordered microdomains (lipid rafts) play a key role not only in the lateral heterogeneity properties of the capacitating sperm, but more explicitly are instrumental for both zona binding and the zona-induced acrosome reaction.

\section{Detection of lateral diffusion}

In the early seventies, it was first recognized that membrane components show lateral diffusion. The fluid mosaic model (Singer and Nicolson, 1972) was proposed as a prediction as to how
It was also shown that a large proportion of the phospholipids were able to diffuse over the surface area of the membrane (lateral diffusion; Scandella et al., 1972). Under physiological conditions, the immobile phospholipid fraction was immobilized to the cytoskeleton or to the extracellular matrix. The lateral diffusion et al., 1975; Cullis, 1976): Both the amount of cholesterol and the head group composition of the phospholipids, as well as the acyl composition determine the fluidity of the membrane. Below the so called phase transition temperature, the fluid lipids will enter a frozen state in which they do not show lateral diffusion (Feigenson, 1976). The fluid mosaic model also predicted that intrinsic membrane proteins -not associated to the cytoskeleton, the immobile lipid fraction or the extracellular matrix - were also able to diffuse over the surface of a membrane, although their lateral diffusion speed is considerably slower than phospholipids due to the relative larger size of membrane proteins (Cherry, 1979).

The fluid mosaic model did predict a random lateral diffusion over a membrane, whilst in sperm membrane biology, it became apparent that both diffusible membrane proteins as well as lipids where not randomly distributed and even showed a marked redistribution when sperm were incubated under in vitro capacitation conditions (Flesch and Gadella, 2000; Gadella and Visconti, 2006; Jones et al., 2007). Within the sperm membrane, the properties of the lipid bilayer depended on the lipid content (Blok 
relatively low amount of cholesterol, as well as the typical composition of the hydrophobic part of most of the phospholipids (16:0, 22:6 fatty acids), may facilitate surface heterogeneity (Brouwers et al., 1998). Another important aspect to consider is the almost complete absence of cytosol in sperm (Eddy and O'Brien, 1994; Flesch et al., 1998). This implies that the sperm plasma membrane is in almost direct contact with the diverse underlying membranes or cytoskeletal structures, which are highly organized in a very polar fashion. For the sperm head this may explain the different compositions of the post-acrosomal surface (in contact with the nuclear envelope) from the other areas (in contact with the outer acrosomal membrane) (Yanagimachi, 1994). The mid-piece plasma membrane is in contact with the mitochondria, whereas the flagellar plasma membrane is in contact with the outer dense fibers (see Fig. 1).

However, the subdivision of the anterior area of the sperm head into the equatorial region, the pre-equatorial region and the apical ridge, cannot be explained by the intracellular organisation of organelles. Despite the lack of a direct explanation as to the precise causes of this organization, these sperm surface areas are known to be involved in zona binding, the acrosome reaction and the fertilization fusion (see Fig. 2). Freeze fracture replicas of the sperm head membrane established that there is no bilayer spanning structure to prevent mixing of diffusible membrane proteins or lipids (de Leeuw et al., 1990). Nevertheless different surface densities and clustering of membrane particles (remnants of trans-membrane proteins in the replicas) were observed for the above described sperm head surface regions during capacitation (Suzuki and Yanagimachi, 1989). Also, the use of fluorescent membrane probes indicated that the sperm surface is regionalized. The use of fluorescence recovery after photobleaching (FRAP), showed that each of the sperm head surface areas has its own lateral diffusion properties (Wolfe et al., 1998). More recently, an advanced method making use of nanopipette delivery of individual fluorescent molecules into the sperm surface, allowing single-molecule fluorescence tracking using a total internal reflection resonance fluorescence microscope (for specific detection of surface oriented fluorescent molecules), showed the same results (Bruckbauer et al., 2007).

A number of studies report on the polar distribution of sperm surface proteins and lipids and their redistribution during in vitro capacitation. For instance, the eutherian specific seminolipid was highly enriched in the apical ridge area of the sperm head and migrated towards the equatorial area during capacitation, whilst cholesterol showed the retrograde movement (Gadella et al., 1994, 1995). Models predicting that seminolipid (anionically charged) prevents membrane fusion, does not support the hexagonal II phase of phospholipids required for hemifusion of the plasma membrane with the acrosome membrane. Prior to capacitation, the apical ridge oriented seminolipid may prevent the preliminary membrane fusion with the outer acrosomal membrane, while after capacitation the equatorial oriented seminolipid indeed stabilizes this part of the plasma membrane and prevent it from fusion with the outer acrosomal membrane. The equatorial plasma membrane thus becomes continuous with the outer acrosomal membrane and the inner acrosomal membrane (which takes over the function of the apical plasma membrane which is shed of the sperm head after the acrosome reaction (see Fig. 1). The resulting equatorial plasma membrane contains molecules that are allowing sperm-to-egg membrane binding, as well as the intercellular membrane fusion (fertilization fusion). The retrograde movement of cholesterol to the area where the zona binding, as well as the zona induced acrosome reaction takes place, is not easily explained by the fluid mosaic model of cell membranes.

As described above, the fluid mosaic model (Singer and Nicholson, 1972) does not adequately explain the restricted lateral diffusion of membrane molecules of the mammalian sperm surface. Another not yet understood phenomenon is the capacitation-induced redistribution of lateral segregated molecules into other surface specialised membrane areas. With the use of a variety of membrane probes such as lipid fluidity markers (merocyanin), and fluorescent phospholipid analogs, it was demonstrated that the capacitating sperm surface had an increased disordering of the fatty acid chains of the phospholipids and enhanced lateral fluidity as well as a distorted phospholipid asymmetry (Harrison et al., 1996; Gadella and Harrison 2000; Cross, 2003). It was postulated that the partial scrambling of amino phospholipids in the plasma membrane of the apical area of the sperm head is responsible for these phenomona (de Vries et al., 2003).

Interestingly, the group of David Garbers created a null mouse

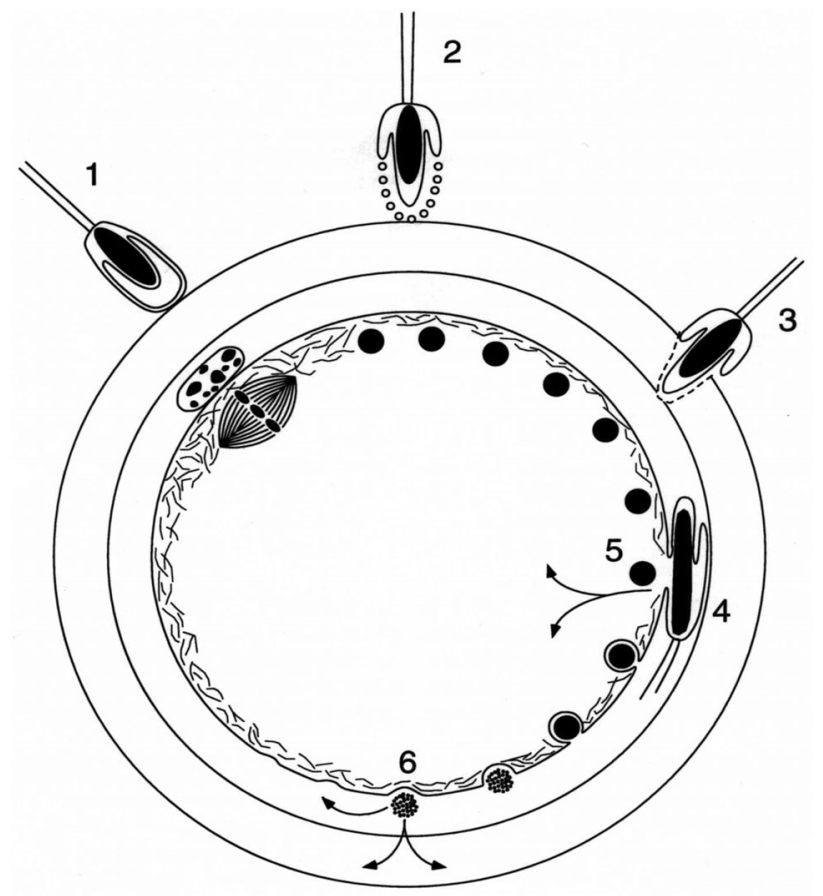

Fig. 2. Schematic representation of the sequence of interactions between the male and female gamete leading to fertilization. (1) Sperm binding to the zona pellucida (restricted to the apical ridge subdomain area); (2) the acrosome reaction (fusions restricted to the apical ridge and pre-equatorial subdomain areas); (3) the penetration of the zona pellucida (note that the equatorial membranes remain intact and that the mixed vesicles resulting from the acrosome reaction are shed from the penetrating sperm); (4) binding and fusion with the egg plasma membrane (restricted to the equatorial subdomain area); (5) activation of the fertilized oocyte by a soluble sperm factors; (6) polyspemy block by the cortical reaction. Modified from Flesch et al., 2000. 
for the sperm specific inward translocase for aminophospholipid (flippase) (Wang et al., 2004). Consequently these mice lacked the translocase establishing the transverse bilayer aminophospholipid asymmetry. This renders the membrane more fluid and thus more vulnerable for preliminary deterioration in the female genital tract. Sperm morphology and motility were the same between null and wild-type littermates but agents (merocyanine and annexin) that measure PS in the outer membrane leaflet showed that PS already existed in the outer leaflet of null spermatozoa before sperm capacitation. Indeed the preliminary scrambling of phospholipids caused fewer transporter(-/-) sperm bound tightly or having penetrated the zona pellucida (ZP) and fewer underwent acrosome reactions. In vitrofertilization (IVF) was compromised, especially at early time points, or at low sperm concentrations after mixing null spermatozoa and eggs. Thus, a new aminophospholipid transporter expressed, exclusively in spermatozoa is critical for normal phospholipid distribution in the bilayer and for normal binding, penetration, and signaling by the zona pellucida.

At the same time our group discovered that the normal bicarbonate mediated scrambling of amino phospholipids in the restricted apical part of the sperm head coincides with increased membrane fluidity and the noted lateral redistribution of seminolipid and of cholesterol (Flesch et al., 2001). Note that this is due to a bicarbonate sensitive activation of a sperm specific scramblase while the translocase -/- mouse had preliminary exposure of PS in the entire sperm surface. The bicarbonate mediated repacking of the sperm surface lipids was essential to allow cholesterol efflux. At that time new discoveries in the general field of membrane biochemistry led to the concept that biomembranes contain lipid-ordered microdomains also called lipid rafts (Simons and Toomre, 2000). Interestingly, those membrane structures were described as being enriched in cholesterol. The importance of cholesterol redistribution and depletion from capacitating sperm cells was at that time already established (Cross 1998; Flesch et al., 2001) and explains why the correlation of cholesterol with sperm membrane raft organization is at the moment a hot research field (see next section).

\section{Sperm membrane microdomains}

The problems a number of spermatologists had with the prediction of the fluid mosaic model of cellular membranes at physiological temperature, was partly explained by the refinement made in this model in the mid 1990s. At this time, the concept of the so called lipid raft, a membrane microdomain containing specific lipids and proteins, was launched (for a review see Simons and Toomre, 2000). These small lipidordered microdomains were supposed to contain larger proportions of cholesterol, sphingomyelin, gangliosides, those phospholipids with saturated long-chain acyl chains, and also lipid modified proteins such as GPI anchored proteins. A few marker proteins were described for lipid rafts: caveolin which is a cholesterol interacting protein involved in clathrin independent endocytosis of caveolae (Elliott et al., 2003; Nabi and Le, 2003) and flotillin, whose function is not yet completely understood, although it has a prohibitin homology (PHB) domain that is supposed to interact with the raft by constituting a primordial lipid recognition motif (Morrow and Parton, 2005). Both caveolin and flotillin are present in mammalian sperm (Travis et al., 2001; Cross, 2004; Sleight et al., 2005). In porcine sperm, both proteins were detected in the plasma membrane over the acrosome in a dispersed, punctuated pattern (van Gestel et al., 2005a). Incubation of Percoll-washed sperm in an IVF medium caused the redistribution of both lipid raft marker proteins into the more confined region of the apical ridge and the labelling appears as a clustering of the punctuated structures that were observed prior to the incubation (van Gestel et al., 2005a). Similar dynamics were described by other groups (Shadan et al., 2004; Cross, 2004; Selvaraj et al., 2007)

Interestingly, it is possible to isolate a detergent resistant membrane (DRM) fraction at $4^{\circ} \mathrm{C}$ using $0.1 \%$ Triton $\mathrm{X}-100$ or similar detergent strength buffers. The non-solubilized membranes floated over a discontinuous density gradient and this floating fraction containing the DRM. Although questionable, it is proposed to represent the lipid raft fraction and is currently the most widespread method to study membrane microdomains (Lingwood and Simons, 2007). The DRM can also be isolated from mammalian sperm (Cross 2004; Sleight et al., 2005; Ermini et al., 2005; van Gestel et al., 2005; Legare et al., 2006; Thaler et al., 2006). The fact that incubation with cyclodextrin can causes solubilisation of the DRM (van Gestel, 2005b) further substantiates that the DRM is reflecting sperm lipid rafts. Cyclodextrin specifically extracts cholesterol from the DRM which causes the solubilisation of this membrane fraction. By means of lipidomics our group has also demonstrated that the DRM is enriched in cholesterol and spingomyelin (van Gestel et al., 2005b and unpublished results).

One could speculate that albumin might act in an analogous fashion to cyclodextrin and induce lipid raft dissociation in capacitating sperm. This idea was postulated by Flesch et al. (2001). In fact, cyclodextrin treatments of sperm have been suggested to induce sperm capacitation but a closer look gave other indications. Albumin extracts some $20 \%$ of cholesterol and only does this from the non-DRM fraction. The amount of cholesterol in the DRM (and the amount of DRM protein) remains similar prior to and after sperm capacitation (van Gestel et al., 2005b and unpublished results). We now believe that the extraction of non-DRM cholesterol provides the possibility of the rafts (represented in the DRM fraction) to aggregate (see van Gestel et al., 2005a). However, cyclodextrin extracts cholesterol from the non DRM and the DRM fraction, causing a dissociation of the lipid rafts (up to $50 \%$ of total cholesterol). The cyclodextrin concentrations where raft dissociation has been observed have also been shown to result in cell death (van Gestel et al., 2005b). Recently, these findings were independently confirmed by the group of Jones (Jones et al., 2007). On the other hand, more subtle approaches to deplete cholesterol from frozen-thawed murine sperm with the use of lower cyclodextrin concentrations and restricted incubation times (30 minutes) were beneficial for mouse IVF using frozen thawed epididymal sperm. The conditions used induced similar aggregation of lipid rafts (Jones et al., 2007) in the sperm plasma membrane as has been shown to occur for albumin treated sperm (van Gestel et al., 2005a). Therefore, care has to be taken of the concentration and incubation duration with cyclodextrins and the comparison of cyclodextrins -mediated 
alterations in lipid-ordered sperm membrane microdomains and those affected by albumin.

\section{Sperm membrane microdomains and the zona binding}

Recently, we have used a nitrogen cavitation method to isolate the apical plasma membrane fraction of mammalian sperm (APM; Flesch et al., 1998). We have used the APM preparations to detect which proteins were involved in the primary binding of sperm to the zona pellucida. A whole sperm homogenate cannot be used as it is loaded with secondary zona binding proteins from the acrosome. As is described in section 1, the sperm makes initial contact with the zona pellucida with the apical tip of the sperm head. If other membrane areas of the sperm cells were involved in zona recognition this would (from an ergonomic point of view) frustrate sperm zona drilling.

This purification of APM results in membrane preparations of the area that is exclusively involved in zona recognition and is a valuable tool to enrich for those molecules devoted to primary sperm zona binding. The APM preparations were incubated with zona ghosts isolated from mature porcine follicles. Those proteins with affinity for the zona ghosts were identified using proteomic techniques (protein separation by 2D electrophoresis and protein identification by tandem mass spectrometry) (van Gestel et al., 2007). In a parallel study, we isolated DRM from sperm and identified the most prominent proteins in the DRM that were not detectable in the non-DRM (van Gestel et al., 2005a). Interestingly, a number of proteins that were detected as zona binding proteins from the APM were highly specific for the clustered DRM. These identified proteins were also described in the literature as zona binding proteins, including: AQN-3 (also known as spermadhesin; Calvete et al., 1996), P47 (the porcine homologue of SED1, Ensslin et al., 1998; Ensslin and Shur, 2007) and fertilin beta (Yamagata et al., 2002). Fertilin-beta is a transmembrane protein thought to function as an adhesion molecule for the zona pellucida; it was shown to have no function in sperm-egg membrane fusion as reported previously (Yamagata et al., 2002). The other two zona binding proteins AQN-3/spermadhesin and P47/ SED-1, are secretory proteins from the epididymidal epithelium. Both proteins become firmly attached to phospholipids of the outer lipid leaflet of the sperm surface and remain there after Percoll washing and IVF incubation, or even after treatment with high salt. Both proteins have a restricted distribution in the anterior tip of the sperm head surface (i.e. the area involved in initial sperm-zona binding) (Petrunkina et al., 2003; Ensslin et al., 1998)

Likewise, it has been recently demonstrated that many GPI anchored proteins, which are highly exclusive for the DRM, and thus considered to be specific for lipid rafts (for review see Hooper, 1999), are acquired by the surface of the maturing sperm cell by epididymosomes (Sullivan et al., 2007). Epididymsomes are apocrine-secreted, tiny membraneous vesicles, also called exosomes, that originate from the epithelium of the epididymal tract (Frenette and Sullivan, 2001; Hermo and Jacks, 2002). It has been demonstrated that GPI-anchored proteins from epididymososmes can be linked to the sperm surface after surface contact and that mouse sperm contain epididymal originated GPI anchored proteins. Examples are CD52 (also called HE5) for human sperm (Yeung et al., 2001; Ermini et al., 2005) and SPAM-1 (also called PH20, P26h,P25b) in a variety of mammalian species (Phelps et al., 1988; Thaler and Cardullo, 1995; Zhang and Martin-Deleon, 2003; Frenette and Sullivan, 2001). It is of interest that we determined the protein carbonyl reductase as one of the zona binding proteins (van Gestel et al., 2005a). In the hamster this enzyme is in the same fraction as P26h (Montford et al., 2002), which may indicate that carbonyl reductase is another GPI anchored protein involved in zona binding. It is not yet clear how these GPI-anchored proteins are placed in the sperm surface, although there are indications from other biological specimens that lipoprotein particles are mediating transfer of GPI-anchored proteins from a donor to a target membrane (Neumann et al., 2007). The high enrichment of zona binding proteins in the DRM and the clustering of raft markers in the apical ridge area of the sperm head, exactly matching the sperm-zona recognition area, indicate that the redistribution of lipid ordered membrane domains in sperm cells are contributing to the zona binding event.

\section{Sperm microdomains and the acrosome reaction}

Of course the next step en route to the fertilization event is the zona-induced acrosome reaction. Since we have indications that the lipid ordered membrane microdomains are clustering in the apical ridge are of the sperm head and are also involved in the zona recognition, we have looked for the distribution of proteins involved in the acrosome reaction. This is a multiple membrane point fusion event induced by the zona pellucida and takes place between the plasma membrane and the outer acrosomal membrane (see Fig. 1). Like other examples of intracellular membrane fusion, it is generally believed that soluble $\mathrm{N}$-ethylmaleimide sensitive factor attachment protein receptor proteins (SNAREs) are involved in this process (for a recent review see Mayorga et al., 2007). Many proteins involved in the regulation and formation of a SNARE fusion protein complex in mammalian sperm have been identified using streptolysin-treated sperm. Although useful to identify putative candidates involved in the acrosome secretion, we recently published a more biochemical approach to identify and localize two different syntaxins (syntaxin 1 and 2) in the sperm plasma membrane (Tsai et al., 2007). Interestingly, the syntaxins show similar lateral distribution as flotillin. They were exclusively recovered in the APM and absent in the sperm tail and mid-piece as well as in intracellular structures of the sperm head. The syntaxins were distributed in a punctuated, dispersed pattern over the acrosome overlying surface area of the sperm, but were not present in the equatorial area of the sperm head, or in the postacrosomal area. After in vitro capacitation, these syntaxins migrated to the apical ridge area and a substantial proportion of these syntaxins were recovered in the DRM fraction. These observations confirm co-localisation of SNARE proteins and caveolin as described earlier (Gamboa and Ramaho-Santos, 2005; Sousa etal., 2006). The syntaxins were not recovered in the DRM fraction when in vitro capacitation was induced in the absence of one or more of the capacitation factors: bicarbonate, calcium ions and albumin. The SNARE proteins from the outer acrosomal membrane (vesicle-associated membrane proteins VAMP 1 and 2) also show a similar redistribution in the sperm head as they migrated from the pre-equatorial surface towards the apical ridge area and showed recovery in the DRM fraction 
(Tsai et al., 2007).

Current research is determining whether the acrosome membrane polarity of VAMP is caused by the docking of VAMP to syntaxin (explaining its redistribution on the sperm surface and its extraction in the DRM), or that the sperm acrosome also contains lipid rafts that are subjected to capacitation induced redistribution. For each of the two possibilities we have preliminary evidence (Tsai et al., unpublished results). Besides the necessity of SNARE proteins for the acrosomal fusion, the group of Ackermann et al. (2007) described a lipid-raft associated scaffolding protein to be involved in acrosome to plasma membrane docking and that the syntaxins and VAMP were later (after tethering) involved in the execution of the acrosomal fusions. An additional group has found that Rab3A has a tethering role between the sperm plasma and outer acrosomal membranes and plays a role in the SNARE complex assembly and the $\mathrm{Ca}^{2+}$ mediated activation of synaptotagmin (Yunes et al., 2000; Mayorga et al., 2007; Lopez et al., 2007). It is already clear that the sperm acrosome has a differentiated membrane, because VAMP 1 and 2 are not present in the equatorial part of the acrosome and are also absent in the inner acrosomal membrane. After in vitro capacitation they are even further restricted in the apical ridge area of the acrosome.

In this light it is interesting to note that the integral acrosome membrane protein zonadhesin is also confined to specific parts of the outer acrosomal membrane (Lea et al., 2001) and that after capacitation a more restricted area of the outer acrosomal membrane is occupied with zonadhesin even under detergent conditions that were similar to those used to prepare DRM (Olson et al., 2004). This may indicate that capacitation-dependent processing and lateral redistribution of outer acrosomal membrane proteins into the putative lipid-ordered domain of this membrane not only contributes to the zona-induced acrosome reaction (by recruiting VAMP proteins), but also recruits secondary zona binding proteins to the anterior part of the acrosome in order to guarantee maximal secondary zona binding and zona penetration immediately after the acrosome reaction.

\section{Conclusion}

In this review we have aimed to emphasize the role of the sperm membrane heterogeneity in the cascade of processes leading to the fertilization of the oocyte. In particular, the formation of lipid ordered microdomains in the sperm surface appears to be relevant for sperm-zona binding and the zona-induced acrosome reaction. Proteomic approaches have revealed that epididymal maturation is an important process for the addition of phospholipid interacting and GPI anchored proteins. At least some of those proteins that remain associated to the sperm after IVF treatments have been shown to be involved in sperm-zona binding. We also have indications that the lipid rafts are surface specialisations that link sperm-zona binding to the zona induced acrosome reaction as the plasma membrane and outer acrosomal membrane SNARE proteins involved in this process migrate into the lipid rafts and cluster in the apical ridge area.

However, we do not yet know how this IVF situation compares to the physiological situation where sperm have to migrate to the female genital tract and will interact with the cumulus oocyte complex somewhere in the isthmus region of the oviduct. It is certainly possible that the uterus and/or oviduct epithelium is involved in further sperm surface remodelling allowing more efficient sperm-zona interaction and the zona induced acrosome reaction. Although such studies would involve more tedious approaches to obtain relevant data, they may shed light on what we normally bypass in the IVF clinic to achieve fertilization. Further understanding of the role of uterus/oviduct proteins in sperm-oocyte interactions may help us to define new strategies to overcome infertility problems or to design new contraceptives to prevent fertility.

\section{Acknowledgements}

Part of this reviewis based on the results of two PhD students that have worked in both laboratories and we thank Dr. F.M. Flesch and Dr. R.A. van Gestel for their help. The Dutch Research Council (NWO-MW grant number 903-44-156), the Institute of Veterinary Sciences, and the High Potential Program of Utrecht University are thanked for their support.

\section{References}

ACKERMANN, F., ZITRANSKI, N., HEYDECKE D., WILHELM, B. GUDERMANN,nT., BOEKHOFF, I. (2008). The Multi-PDZ domain protein MUPP1 as a lipid raft-associated scaffolding protein controlling the acrosome reaction in mammalian spermatozoa. J. Cell. Physiol. 214:757-68.

BLOK M.C., van der NEUT-KOK E.C., van DEENEN L.L., de GIER J. (1975). The effect of chain length and lipid phase transitions on the selective permeability properties of liposomes. Biochim. Biophys. Acta 406:187-96.

BROUWERS, J.F., GADELLA, B.M., van GOLDE, L.M., TIELENS, A.G. (1998). Quantitative analysis of phosphatidylcholine molecular species using HPLC and light scattering detection. J. Lipid Res. 39:344-53.

BRUCKBAUER, A., JAMES, P., ZHOU, D., YOON, J.W., EXCELL, D., KORCHEV, Y., JONES, R., KLENERMAN, D. (2007). Nanopipette delivery of individual molecules to cellular compartments for single-molecule fluorescence tracking. Biophys. J. 93:3120-31.

CALVETE, J.J., CARRERA, E., SANZ, L., TOPFER-PETERSEN, E. (1996). Boar spermadhesins $A Q N-1$ and $A Q N-3$ : oligosaccharide and zona pellucida binding characteristics. Biol. Chem. 377:521-7.

CHAPMAN, D. (1975). Fluidity and phase transitions of cell membranes. Biomembranes 7:1-9.

CHERRY, R.J. (1979). Rotational and lateral diffusion of membrane proteins. Biochim. Biophys. Acta 559:289-327.

CROSS, N.L. (1998). Role of cholesterol in sperm capacitation. Biol. Reprod. 59:711.

CROSS, N.L. (2003). Decrease in order of human sperm lipids during capacitation. Biol. Reprod. 69:529-34.

CROSS, N.L. (2004). Reorganization of lipid rafts during capacitation of human sperm. Biol. Reprod. 71:1367-73.

CULLIS, P.R. (1976). Lateral diffusion rates of phosphatidylcholine in vesicle membranes: effects of cholesterol and hydrocarbon phase transitions. FEBS Lett. 70:223-8.

De LEEUW, F.E., CHEN, H.C., COLENBRANDER, B., VERKLEIJ, A.J. (1990). Cold-induced ultrastructural changes in bull and boar sperm plasma membranes. Cryobiology 27:171-83.

DEVEAUX, P.F., LOPEZ-MONTERO, I., BRYDE, S. (2006). Proteins involved in lipid translocation in eukaryotic cells. Chem. Phys. Lipids 141:119-32.

De VRIES, K.J., WIEDMER, T., SIMS, P.J., GADELLA, B.M. (2003). Caspaseindependent exposure of aminophospholipids and tyrosine phosphorylation in bicarbonate responsive human sperm cells. Biol. Reprod. 68:2122-34.

EDDY, E.M., O'BRIEN, D. (1994). Mammalian fertilization. In: Knobil E, Neill JD editors. The physiology of reproduction (2nd edition). New York, USA: Raven Press p.29-78.

ELLIOTT, M.H., FLIESLER, S.J., GHALAYINI, A.J. (2003). Cholesterol-dependent association of caveolin-1 with the transducin alpha subunit in bovine photoreceptor rod outer segments: disruption by cyclodextrin and guanosine 5'-O-(3- 
thiotriphosphate). Biochemistry 42:7892-903.

ENSSLIN, M., VOGEL, T., CALVETE, J.J., THOLE, H.H., SCHMIDTKE, J., MATSUDA, T., TPFER-PETERSEN, E. (1998). Molecular cloning and characterization of $\mathrm{P} 47$, a novel boar sperm-associated zona pellucida-binding protein homologous to a family of mammalian secretory proteins. Biol. Reprod. 58:105764.

ENSSLIN, M.A., SHUR, B.D. (2003). Identification of mouse sperm SED1, a bimotif EGF repeat and discoidin-domain protein involved in sperm-egg binding. Cel/ 114:405-17.

ERMINI, L., SECCIANI, F., LA SALA, G.B., SABATINI, L., FINESCHI, D., HALE, G., ROSATI, F. (2005). Different glycoforms of the human GPI-anchored antigen CD52 associate differently with lipid microdomains in leukocytes and sperm membranes. Biochem. Biophys. Res. Commun. 338:1275-83.

FEIGENSON, G.W. (2006). Phase behavior of lipid mixtures. Nat. Chem. Biol. 2:560-3.

FLESCH, F.M., BROUWERS, J.F., NIEVELSTEIN, P.F., VERKLEIJ, A.J., van GOLDE, L.M., COLENBRANDER, B., GADELLA, B.M. (2001). Bicarbonate stimulated phospholipid scrambling induces cholesterol redistribution and enables cholesterol depletion in the sperm plasma membrane. J. Cell Sci. 114:3543-55

FLESCH, F.M., COLENBRANDER,'B., van GOLDE, L.M., GADELLA, B.M. (2000). Capacitation induced molecular alterations in the plasma membrane of boar spermatozoa in relation to zona pellucida affinity. In: "Boar Semen". Eds. Johnson LA and Guthrie HD., Allen Press Inc. Lawrence LS, UISA pp. 21-34.

FLESCH, F.M., GADELLA, B.M. (2000). Dynamics of the mammalian sperm plasma membrane in the process of fertilization. Biochim. Biophys. Acta 1469:197-235.

FLESCH, F.M., VOORHOUT, W.F., COLENBRANDER, B., van GOLDE, L.M., GADELLA, B.M. (1998). Use of lectins to characterize plasma membrane preparations from boar spermatozoa: a novel technique for monitoring membrane purity and quantity. Biol. Reprod. 59:1530-9.

FRENETTE, G., SULLIVAN, R. (2001). Prostasome-like particles are involved in the transfer of P25b from the bovine epididymal fluid to the sperm surface. Mol. Reprod. Dev. 59:115-21.

GADELLA, B.M. (1994). Metabolism and localization of seminolipid in ejaculated mammalian spermatozoa. Thesis, Utrecht University, Elinkwijk Press, Utrecht, The Netherlands pp. 189.

GADELLA, B.M., GADELLA, T.W. Jr., COLENBRANDER, B., van GOLDE, L.M., LOPES-CARDOZO, M. (1994). Visualization and quantification of glycolipid polarity dynamics in the plasma membrane of the mammalian spermatozoon. J. Cell Sci. 107:2151-63.

GADELLA, B.M., LOPES-CARDOZO, M., van GOLDE, L.M., COLENBRANDER, B., GADELLA, T.W. Jr. (1995). Glycolipid migration from the apical to the equatorial subdomains of the sperm head plasma membrane precedes the acrosome reaction. Evidence for a primary capacitation event in boar spermatozoa. J. Cell Sci. 108:935-46.

GADELLA, B.M., HARRISON, R.A. (2000). The capacitating agent bicarbonate induces protein kinase A-dependent changes in phospholipid transbilayer behavior in the sperm plasma membrane. Development 127:2407-20

GADELLA B.M., VISCONTI, P.E. (2006). Regulation of capacitation. In: De Jonge $C$, Barrett $C$, editors. The sperm cell production maturation fertilization regeneration. Cambridge, UK: Cambridge University Press, pp. 134-169.

GAMBOA, S., RAMALHO-SANTOS, J. (2005) SNARE proteins and caveolin-1 in stallion spermatozoa: possible implications for fertility. Theriogenology 64:27591.

HAKOMORI, S., IGARASHI, Y. (1995). Functional role of glycosphingolipids in cell recognition and signaling. J Biochem (Tokyo) 118:1091-103.

HARRISON, R.A., ASHWORTH, P.J., MILLER, N.G. (1996). Bicarbonate/CO2, an effector of capacitation, induces a rapid and reversible change in the lipid architecture of boar sperm plasma membranes. Mol. Reprod. Dev. 45:378-91.

HARRISON, R.A., GADELLA, B.M. (2005). Bicarbonate-induced membrane processing in sperm capacitation. Theriogenology 63:342-51.

HERMO, L., JACKS, D. (2002). Nature's ingenuity: bypassing the classical secretory route via apocrine secretion. Mol. Reprod. Dev. 63:394-410.

HOOPER, N.M. (1999). Detergent-insoluble glycosphingolipid/cholesterol-rich membrane domains, lipid rafts and caveolae. Mol. Membr. Biol. 16:145-56.
JONES, R., JAMES, P.S., HOWES, L., BRUCKBAUER, A., KLENERMAN, D. (2007). Supramolecular organization of the sperm plasma membrane during maturation and capacitation. Asian J. Androl. 9:438-44.

LEA, I.A., SIVASHANMUGAM, P., O'RAND, M.G. (2001). Zonadhesin: characterization, localization, and zona pellucida binding. Biol. Reprod. 65:1691-700.

LEGARE, C., THABET, M., GATTI, J.L., SULLIVAN, R. (2006). HE1/NPC2 status in human reproductive tract and ejaculated spermatozoa: consequence of vasectomy. Mol. Hum. Reprod. 12:461-8.

LINGWOOD, D., SIMONS, K. (2007). Detergent resistance as a tool in membrane research. Nat. Protoc. 2:2159-65.

LOPEZ, C.I., BELMONTE, S.A., De BLAS, G.A., MAYORGA, L.S. (2007). Membrane-permeant Rab3A triggers acrosomal exocytosis in living human sperm. FASEB J. 21:4121-30.

MAYORGA, L.S., TOMES, C.N., BELMONTE, S.A. (2007). Acrosomal exocytosis, a special type of regulated secretion. IUBMB Life 59:286-92.

MONTORT, L., FRENETTE, G., SULLIVAN, R. (2002). Sperm-zona pellucida interaction involves a carbonyl reductase activity in the hamster. Mol. Reprod. Dev. 61:113-9.

MORROW, I.C., PARTON, R.G. (2005). Flotillins and the PHB domain protein family: rafts, worms and anaesthetics. Traffic 6:725-40.

MYLES, D.G., PRIMAKOFF, P. (1984). Localized surface antigens of guinea pig sperm migrate to new regions prior to fertilization. J. Cell Biol. 99:1634-41.

NABI, I.R., Le P.U. (2003). Caveolae/raft-dependent endocytosis. J. Cell Biol. 161:673-7.

NEUMANN, S., HARTERINK, M., SPRONG, H. (2007) Hitch-hiking between cells on lipoprotein particles. Traffic 8: 331-8.

OLSON, G.E., WINFREY, V.P., BI M., HARDY, D.M., NAGDAS, S.K. (2004).Zonadhesin assembly into the hamster sperm acrosomal matrix occurs by distinct targeting strategies during spermiogenesis and maturation in the epididymis. Biol. Reprod. 71:1128-34.

O'RAND, M.G., FISHER S.J. (1987). Localization of zona pellucida binding sites on rabbit spermatozoa and induction of the acrosome reaction by solubilized zonae. Dev. Biol. 119:551-9.

PETRUNKINA, A.M., LÄKAMP, A., GENTZEL, M., EKHLASI-HUNDRIESER, M., TPFER-PETERSEN, E. (2003). Fate of lactadherin P47 during post-testicular maturation and capacitation of boar spermatozoa. Reproduction 125:377-87.

PHELPS, B.M., PRIMAKOFF, P., KOPPEL, D.E., LOW, M.G., MYLES, D.G. (1988) Restricted lateral diffusion of $\mathrm{PH}-20$, a Pl-anchored sperm membrane protein. Science 240:1780-2.

SCANDELLA, C.J., DEVAUX, P., MCCONNEL, H.M. (1972). Rapid lateral diffusion of phospholipids in rabbit sarcoplasmic reticulum. Proc. Natt. Acad. Sci. USA 69:2056-60.

SELVARAJ, V., BUTTKE, D.E., ASANO, A., MCELWEE, J.L., WOLFF, C.A., NELSON, J.L, KLAUS, A.V., HUNNICUTT, G.R., TRAVIS, A.J. (2007). GM1 dynamics as a marker for membrane changes associated with the process of capacitation in murine and bovine spermatozoa. J. Androl. 28:588-99.

SIMONS, K., TOOMRE, D. (2000). Lipid rafts and signal transduction. Nat. Rev. Mol. Cell Biol. 1:31-9.

SINGER, S.J., NICOLSON, G.L. (1972). The fluid mosaic model of the structure of cell membranes. Science 175:720-31.

SHADAN, S., JAMES, P.S., HOWES, E.A., JONES, R. (2004). Cholesterol efflux alters lipid raft stability and distribution during capacitation of boar spermatozoa. Biol. Reprod. 71:253-65

SLEIGHT, S.B., MIRANDA, P.V., PLASKETT, N.W., MAIER, B., LYSIAK, J., SCRABLE, H., HERR, J.C., VISCONTI, P.E. (2005). Isolation and proteomic analysis of mouse sperm detergent-resistant membrane fractions: evidence for dissociation of lipid rafts during capacitation. Biol. Reprod. 73:721-9.

SOUSA, A.P., GOMES-SANTOS C.S., RAMALHO-SANTOS, J. (2006). Localization of SNAREs, NSF and Caveolin 1 in human spermatozoa: relationship with seminal parameters. Arch. Androl. 52:347-53.

SULLIVAN, R., FRENETTE, G., GIROUARD, J. (2007). Epididymosomes are involved in the acquisition of new sperm proteins during epididymal transit. Asian J. Androl. 9:483-91.

SUZUKI, F., YANAGIMACHI, R. (1989). Changes in the distribution of intramembranous particles and filipin-reactive membrane sterols during in vitro capacita- 
tion of golden hamster spermatozoa. Gamete Res. 23:335-47.

SUZUKI-TOYOTA, F., ITOH, Y., NAITO, K. (2000). Reduction of intramembranous particles in the periacrosomal plasma membrane of boar spermatozoa during in vitro capacitation: a statistical study. Dev. Growth Differ. 42:265-73.

THALER, C.D., CARDULLO, R.A. (1995). Biochemical characterization of a glycosylphosphatidylinositol-linked hyaluronidase on mouse sperm. Biochemistry 34:7788-95.

THALER, C.D., THOMAS, M., RAMALIE, J.R. (2006). Reorganization of mouse sperm lipid rafts by capacitation. Mol. Reprod. Dev. 73:1541-9.

TRAVIS, A.J., MERDIUSHEV, T., VARGAS, L.A., JONES, B.H., PURDON, M.A., NIPPER, R.W., GALATIOTO, J., MOSS, S.B., HUNNICUTT, G.R., KOPF, G.S. (2001). Expression and localization of caveolin-1, and the presence of membrane rafts, in mouse and Guinea pig spermatozoa. Dev. Biol. 240:599-610.

TSAI, P.S., De VRIES, K.J., De BOER-BROUWER M., GARCIA-GIL, N., VAN GESTEL R.A., COLENBRANDER B., GADELLA, B.M., Van HAEFTEN, T. (2007). Syntaxin and VAMP association with lipid rafts depends on cholesterol depletion in capacitating sperm cells. Mol. Membr. Biol. 24:313-24.

van GESTEL, R.A., BREWIS, I.A., ASHTON, P.R., BROUWERS, J.F., GADELLA, B.M. (2007). Multiple proteins present in purified porcine sperm apical plasma membranes interact with the zona pellucida. Mol. Hum. Reprod. 13:445-454.

van GESTEL, R.A., BREWIS, I.A., ASHTON, P.R, HELMS, J.B., BROUWERS, J.F. GADELLA, B.M. (2005a).Capacitation-dependent concentration of lipid rafts in the apical ridge head area of porcine sperm cells. Mol. Hum. Reprod. 11:58390.

van GESTEL, R.A., HELMS, J.B., BROUWERS, J.F., GADELLA, B.M. (2005b). Effects of methyl-beta-cyclodextrin-mediated cholesterol depletion in porcine sperm compared to somatic cells. Mol. Reprod. Dev. 72:386-95
VERKLEIJ, A.J., ZWAAL, R.F., ROELOFSEN, B., COMFURIUS, P., KASTELIJN, D., Van DEENEN, L.L. (1973). The asymmetric distribution of phospholipids in the human red cell membrane. A combined study using phospholipases and freeze-etch electron microscopy. Biochim. Biophys. Acta 323:178-93.

WANG, L., BESSERRA, C., GARBERS, D.L. (2004). A novel aminophospholipid transporter exclusively expressed in spermatozoa is required for membrane lipid asymmetry and normal fertilization. Dev. Biol. 267:203-15.

WOLFE, C.A., JAMES, P.S., MACKIE, A.R., LADHA, S., JONES, R (1998). Regionalized lipid diffusion in the plasma membrane of mammalian spermatozoa. Biol. Reprod. 59:1506-14.

YAMAGATA, K., NAKANISHI, T., IKAWA, M., YAMAGUCHI, R., MOSS, S.B., OKABE, M. (2002). Sperm from the calmegin-deficient mouse have normal abilities for binding and fusion to the egg plasma membrane. Dev. Biol. 250:34857.

YANAGIMACHI, R. (1994). Mammalian fertilization. In: Knobil E, Neill JD editors. The physiology of reproduction (2nd edition). New York, USA: Raven Press;pp. 189-317.

YEUNG, C.H., PREZ-SNCHEZ, F., SCHRTER, S., KIRCHOFF, C., COOPER, T.G. (2001). Changes of the major sperm maturation-associated epididymal protein HE5 (CD52) on human ejaculated spermatozoa during incubation. Mol. Hum. Reprod. 7:617-24.

YUNES, R., MICHAUT, M., TOMES, C., MAYORGA, L.S. (2000). Rab3A triggers the acrosome reaction in permeabilized human spermatozoa. Biol. Reprod. 62:1084-9.

ZHANG, H., MARTIN-DELEON, P.A. (2003). Mouse epididymal Spam1 $(\mathrm{pH}-20)$ is released in the luminal fluid with its lipid anchor. J. Androl. 24:51-8. 


\section{Related, previously published Int. J. Dev. Biol. articles}

See our recent Special Issue Developmental Biology in Poland edited by Tarkowski, Maleszewski and Kloc at: http://www.ijdb.ehu.es/web/contents.php?vol=52\&issue=2-3

See our recent Special Issue Developmental Morphodynamics edited by Richard Gordon and Lev Beloussov at: http://www.ijdb.ehu.es/web/contents.php?vol=50\&issue=2-3

\section{Glycobiology of fertilization in the pig}

Edda Töpfer-Petersen, Mahnaz Ekhlasi-Hundrieser and Miroslava Tsolova Int. J. Dev. Biol. (2008) 52: 717-736

Mammalian fertilization:the egg's multifunctional zona pellucida

Paul M. Wassarman and Eveline S. Litscher

Int. J. Dev. Biol. (2008) 52: 2524-2524

CpZPC, a newt ZPC molecule, localizes to the inner surface of the egg envelope. Youko Makabe-Kobayashi, Etsuko Kudaira, Akihiko Watanabe and Kazuo Onitake Int. J. Dev. Biol. (2003) 47: 51-58

2P1, a novel male mouse cDNA specifically expressed during meiosis.

Sonia Hammami-Hamza, Mireille Doussau, Isabelle Allemand, Dominique Segretain, Jean-Marie Gasc and Catherine Finaz Int. J. Dev. Biol. (2003) 47: 71-76

Association of egg zona pellucida glycoprotein mZP3 with sperm protein sp56 during fertilization in mice.

$\mathrm{N}$ Cohen and $\mathrm{P} M$ Wassarman

Int. J. Dev. Biol. (2001) 45: 569-576

Sperm-egg interaction at fertilization: glycans as recognition signals. F Rosati, A Capone, C D Giovampaola, C Brettoni and R Focarelli Int. J. Dev. Biol. (2000) 44: 609-618

Analysis of polysulfate-binding domains in porcine proacrosin, a putative zona adhesion protein from mammalian spermatozoa.

$S$ Jansen, M Quigley, W Reik and R Jones

Int. J. Dev. Biol. (1995) 39: 501-510

Egg-jelly signal molecules for triggering the acrosome reaction in starfish spermatozoa.

M Hoshi, T Nishigaki, A Ushiyama, T Okinaga, K Chiba and M Matsumoto Int. J. Dev. Biol. (1994) 38: 167-174

Failure of differentiation of the nuclear-perinuclear skeletal complex in the roundheaded human spermatozoa.

D Escalier

Int. J. Dev. Biol. (1990) 34: 287-297

2006 ISI ${ }^{* \star}$ Impact Factor $=3.577^{\star \star}$

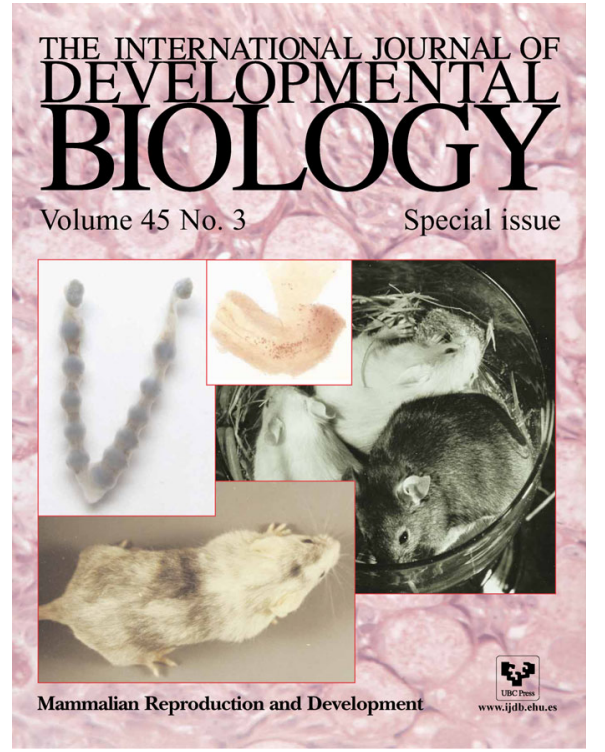

